\title{
LA INDUSTRIA TURÍSTICA Y SUS EFECTOS EN LA ECONOMÍA MUNDIAL - CASO PERUANO. POLÍTICA ESTATAL
}

\author{
SIXTILIO DALMAU CASTAÑÓN \\ E-mail: sdalmau@inat.edu.pe
}

Un desarrollo rápido y continuo: ésta es desde hace muchos años una de las principales características del turismo nacional e internacional.

En 1963, en Roma, las Naciones Unidas proclamaron que "el turismo es una actividad humana fundamental y eminentemente deseable que merece el elogio y estímulo de todos los pueblos y gobiernos. Esta conferencia reconoció también el importante papel que el turismo representa fortaleciendo la economía de los países, estimulando el comercio internacional, generando renta en forma de empleo, fomentando el ingreso de divisas, redistribuyendo la renta interna y suscitando la armonía y la comprensión internacionales. A fin de reconocer el útil papel concedido al turismo, en los campos social, cultural y educativo, la Asamblea General de las Naciones Unidades, proclamó a 1967 como "año internacional del turismo". Este acontecimiento revistió una importancia crucial, confiriendo al turismo la plenitud de su madurez como parte integrante de la actividad nacional e internacional.

El turismo tiene un papel fundamental, en una medida siempre creciente, para poner más en evidencia las dimensiones sociales de los cambios económicos en la búsqueda de objetivos cualitativos -en oposición a los objetivos meramente cuantitativos que imperan en el país- de desarrollo y modernización que los organismos inter- nacionales han fijado durante el curso de los años. El turismo conforma numerosos aspectos. Es una actividad multiformal que penetra en casi todos los sectores de la vida de una nación. El turismo afecta a numerosos campos de acción a los que no siempre se superpone exactamente.

Tomado en su más amplio sentido, el turismo es la acción de viajar que lleva a cabo el turista, en el extranjero o en su país, de la misma manera que el excursionista. Pero engloba también las actividades desplegadas para ofrecer los servicios que todos estos turistas, en formas tan numerosas como variadas, requieren.

El turismo no es un sector seccionado, sino que está implicado en todos los sectores de actividad sobre los que hace sentir su influencia. Debe considerarse globalmente y no desde una óptica sectorial como acontece en el Perú, guardando en la mente el conjunto de sus componentes sociales, culturales, políticos, educativos y económicos. El turismo es más bien un mercado que una industria. No es productor de bienes materiales, sino de servicios, son numerosas las ramas de servicios que abastecen las necesidades de los turistas, pero la medida en que se convierten en ramas propiamente turísticas depende del grado en que éstas se basan en el turismo.

Según la definición generalmente aceptada, los turistas son los visitantes temporales que efec- 
tuán una estancia de al menos 24 horas en el país o ciudad visitado y cuyos motivos de viaje pueden agruparse en ocio, tiempo libre, vacaciones, salud, estudios, religiôn, deportes, familia, misión, congresos y reuniones, y, finalmente, negocios. Así pues, el turismo no significa únicamente desplazamientos para la distracción o el placer, sino que comprende también los viajes de negocios y los desplazamientos motivados por toda una serie de otras razones personales, a exclusión de la búsqueda de un empleo remunerado.

Resulta interesante considerar el desarrollo del turismo durante los últimos 48 años. En 1950 las llegadas de turistas internacionales se elevaban a 25 millones, y el total de ingresos procedentes del turismo internacional alcanzaba la cifra de 2,100 millones de dólares. En 1970, las llegadas de turistas internacionales se elevaban a 169 millones, $y$ el total de ingresos procedentes del turismo internacional llegaba a la cifra de 17,900 millones de dólares. En 1996 las llegadas a nivel mundial alcanzan la cifra de 594 millones y el total de ingresos por turismo a nivel mundial, excluidos los ingresos por transporte, llegan a la colosal cifra de 125,047 millones de dólares. A las Américas llegaron este mismo año 111 millones de personas y al Perú, $600 \mathrm{mil}$, como para sacar conclusiones acerca del optimismo reinante.

El turismo moderno es un producto directo de la evolución social y económica derivada de los progresos técnicos y científicos. Ingresos más altos, mayor tiempo para el ocio, expansion demográfica y establecimiento de instalaciones turísticas cuyo precio disminuye a la vez que su variedad aumenta, son factores que contribuyen esencialmente al desarrollo del turismo. Una enseñanza más avanzada ha creado una mayor toma de conciencia en materia cultural, estimulando el deseo de viajar. Los progresos realizados por la industrialización y el urbanismo han contribuido a crear, desde el punto de vista psicológico, una cierta propensión a la movilidad, así como una urgente necesidad de descanso y distracción. Una aguda preocupación por el bienestar social ha conducido a numerosos gobiernos a adoptar medidas a favor de vacaciones más largas.
Las economías nacionales son cada vez más interdependientes, y el carácter multinacional de los negocios, de la ciencia y de la industria, se acrecienta sin cesar. Así, el volumen del tráfico y de las transacciones entre los países aumenta consecuentemente.

Debido al impacto del turismo en numerosos sectores de la vida nacional, resulta a veces difícil estimar bajo una forma muy precisa su importancia social y económica. La función que el turismo juega en la eçonomía es, sin embargo, evidentc.

En las regiones desprovistas de otras industrias, el turismo contribuye a corregir el desequilibrio económico, participando, a la vez y con éxito, en la lucha contra el éxodo de las poblaciones en las zonas rurales y montañosas.

Según numerosos expertos, el turismo ocupa el primer puesto en los intercambios internacionales. Los gastes de los turistas extranjeros y las inversiones en eapitales de otros países para la construcción de instalaciones, hacen del turismo una incontestable fuente de divisas. En muchos países, los ingresos procedentes del turismo representan entre el $15 \%$ y $30 \%$ del total de exportaciones de bienes y servicios. El turismo sirve frecuentemente para cubrir el déficit de los intercambios comerciales mejorando, por otro lado, la situación de la balanza de pagos.

El movimiento monetario puesto en circulación por los gastos de los turistas, aumenta a medida que se atraviesan los distintos sectores de la economía: es lo que se llama su "efecto multiplicador". Este efecto multiplicador asegura el reparto de los beneficios debido al desarrollo del turismo entre la mayor parte posible de la población.

El desarrollo del sector terciario -el referente a los servicios-beneficia, directamente, gracias al turismo, a los sectores primario y secundario por el hecho de que el turismo suscita un crecimiento de la demanda de bienes y artículos de estos sectores, además, haciendo figurar el turismo en los proyectos de desarrollo económico general, se llega a mitigar sensiblemente el costo del desarrollo.

Calculando lo que reportan las inversiones 
realizadas en el turismo, los encargados de la política turística de un país no podrán limitarse a consideraciones estrechas de rentabilidad financiera y económica inmediatas sino que deberán tener en cuenta los efectos favorables del turismo en el desarrollo nacional global, campo en el que las preocupaciones de tipo social pueden tener una importancia igual o superior a la de las ventajas de carácter meramente económico; se trata de consideraciones culturales como la protección de la herencia de la nación, sociales, como el establecimiento de un equipo recreativo y de instalaciones de bienestar para la población; políticas como una mejor comprensión nacional e internacional; etc.

Los beneficios sociales y económicos del progreso técnico en los últimos años, han ampliado considerablemente el mercado turístico, al extremo de concluir aseverando que el total de los gastos dedicados a los viajes internacionales tiene tendencia a aumentar a un ritmo aproximado al doble del índice de crecimiento de las rentas nacionales. Sin embargo debemos tener presente, según informa la Organización Mundial del Turismo (OMT), en la mayoría de los principales destinos turísticos el turismo ha sobrepasado esta proporción.

La demanda turística es de las más heterogéneas y diversificadas por diferentes motivos que paso a reseñar:

- Por su composición desde el punto de vista de los diversos grupos de edad y de las distintas categorías de rentas a que los turistas pertenecen

- Por su motivación: distracción, cultura, educación, negocios, religión, deportes y otros Por la elección de los puntos de destino: estaciones de montaña, playas, ciudades artísticas, centros industriales, aglomeraciones

- Por la elección de los medios de transporte: ferrocarril, carretera, mar, aire, y

- Por la elección del tipo de vacaciones: Itinerante o estancia en lugares previamente elegidos.

También tenemos que referirnos a la introducción de diversos tipos de facilidades, es decir de viajes más baratos, y a la elevación de la renta, que han permitido que personas pertenecientes a sectores cada vez más amplios de la población puedan viajar en número más creciente.

La ampliación y diversificación de la demanda turística ha suscitado paralelamente una expansión y una modificación del tipo, extensión y estructura de los equipos turísticos. Son muy numerosos los gobiernos que han acordado diversas formas de ayuda financiera y de desgravaciones fiscales a fin de estimular las inversiones en las instalaciones turísticas. Estas ayudas consisten en préstamos a largo plazo y a escaso interés, exención de derechos de aduana para la importación del material necesario, disposiciones especiales para atraer los capitales extranjeros y exención del IGV a los turistas, con lo que han logrado conseguir una posición prioritaria y un estatuto de industria de exportación.

En lo relativo a los viajes de placer, la demanda es muy elástica y, por lo tanto, muy sensible a las variaciones de precios; de ahí la importancia de determinación de precios para el mercado turístico. El Estado y los operadores turísticos deben unificar sus esfuerzos para ofrecer a un precio mas bajo fórmulas de vacaciones a forfait. De ello ha resultado un apreciable incremento de los charteres o vuelos fletados organizados por grandes unidades integradas que sitúan las vacaciones en los lugares elegidos. La introducción de métodos de producción de masa tendientes a reducir el precio de los viajes para hacer frente a la diferenciación cualitativa de la demanda turística, hace que se encuentre en vías de realización una verdadera industrialización del turismo.

Por ello, considero que las perspectivas que ofrece el crecimiento del turismo son muy favorables, dado que están ligádas al mantenimiento de condiciones económicas estables que, sin duda, favorecerá un ritmo de crecimiento económico elevado, el pleno empleo y la reducción de la diferencia de renta entre países desarrollados y los considerados en "vías de desarrollo". El crecimiento general de la economía significará que el consumidor podrá disponer de un margen mayor de renta con el consiguiente incremento de la demanda turística. 
Frente a este análisis, debidamente apoyado en las investigaciones formuladas por organizaciones internacionales, tenemos para la comprensión final, la posición del sector turismo expuesta en el Seminario ALTUR - 97 en la que señala puntualmente ( $\mathrm{sic}$ ), el accionar del gobiemo a este respecto:

- Calidad versus cantidad en cuanto al flujo turístico

- Preservación de los recursos

- Elevar, a través de la capacitación, la competitividad del producto peruano
- Diversificar las modalidades de turismo: arqueologico, termalístico, deportivo

- Mejorar la calidad de los servicios

- Mejoramiento de la conciencia turistica

- Promoción de destino Perí, a través de las principales ferias internacionales

- Incrementar los incentivos para el desarrollo del sector

- Diversificar los productos turísticos

- Incrementar el apoyo del sector al CENFOTUR

Ustedes, lectores, saquen sus propias conclusiones. 